\title{
Should the Internet be Everywhere? Perspectives on Ubiquitous Internet Access*
}

Paper presented to the Association of Internet Researchers Conference (AOIR 5.0) University of Sussex, UK, September 2004

Teresa Ritter, York University, Toronto, Canada

Alison Powell, Concordia University, Montreal, Canada

Catherine Middleton, Ryerson University, Toronto, Canada

The AOIR 5.0 call for papers asks, "Is the internet everywhere?" This paper poses complementary questions: "Should the internet be everywhere?", and if the internet should be ubiquitous, what should it look like? Drawing from Canadian focus group data, the paper explores experienced internet users' opinions and attitudes about the value of the internet, demonstrating that despite its widely recognized benefits, many people embrace the internet somewhat reluctantly. The paper identifies four types of internet users who dynamically engage with the technology in different ways. Each type of user bears a set of distinguishing characteristics, which are drawn from analysis of internet users' discussions about their activities on the internet, and their attitudes toward it. This paper considers how (or whether) ubiquitous internet access could be of benefit to each type of user, concluding that ubiquitous internet access is not yet expected to be in great demand by all types of internet users.

\section{Motivation for the Study and Research Questions}

Internet scholars regularly assume that the internet is a beneficial and useful technology (see Howcroft, 1999, on this point). Governments around the world have embraced this perspective, determining that internet access for all citizens is a fundamental requirement for economic prosperity in the twenty-first century (Broadband Advisory Group, 2002; Computer Science and Telecommunications Board, 2002; International Telecommunication Union, 2003a; National Broadband Task Force, 2001; Office of the e-Envoy, 2001). As more and more citizens

\footnotetext{
This study was funded by the Social Sciences and Humanities Research Council of Canada.
} 
around the world connect to the internet from their homes, and with many homes in North America, Europe and Asia (especially in South Korea, Hong Kong and Japan) adopting broadband internet connections (see the Digital Access Index: International Telecommunication Union, 2003b, for worldwide internet access statistics), many scholars and industry leaders assume that the logical next step in internet development will be ubiquitous internet access (Dixit, 1999; Wanichkorn \& Sirbu, 2002). In fact, broadband internet providers have integrated notions of ubiquity into their corporate strategies and begun marketing packages that offer "more", meaning more content, applications, services, bandwidth and methods of access (e.g. MSN Premium, AOL for Broadband). The beginnings of an industry movement toward ubiquity have also begun with the 'bundling' of internet and mobile services, and with marketing campaigns that advertise internet functionality on mobile devices, suggesting that broadband providers believe there is a market of internet users who want more services.

As will be discussed below, much of the existing research on internet usage tends to categorize internet users on the basis of their experience in using the internet. Experience is measured either by the overall length of time a person has "been online" (e.g. someone who started using the internet in 1995 is considered more experienced than someone who started to use it in 2004), or by the amount of time a person spends online in a given period of time (e.g. a person who spends 20 hours a week online is considered more experienced than someone who spends 4 hours a week online). Many studies have shown that as time spent online increases, users become more comfortable with the internet and increase the range of activities and services that they carry out online (e.g. Rainie, 2004; UCLA Center for Communication Policy, 2003).

Based on the evidence that experienced users spend more time online, and are more comfortable and do more with the internet than inexperienced users, it would follow that as the 
general population of internet users becomes more experienced, there would be more demand for internet access, leading to demand for ubiquitous access. But there is a limitation in this line of reasoning, as it does not consider whether users actually want ubiquitous access, nor does it offer insights as to what form(s) ubiquity should and could take. The shortcoming in research that matches the extent of internet experience with internet activities is that it suggests that experienced internet users are a homogeneous group. The assumption is that as users become experienced, they become more at ease with the internet and continue to use it in multiple ways on an on-going basis, moving more and more of their activities online. But the internet usage behaviours of experienced users cannot be described in homogenous terms, since for instance, some users become internet "dropouts", others integrate the internet into many daily activities while maintaining a distinct separation between those activities and the rest of their lives, and still others embrace the internet for an enormous range of information, communication, and creative applications.

The purpose of this paper is twofold. It begins by challenging the assumption that experienced internet users have homogeneous perspectives of their online experiences, asking, "How do experienced users use the internet?" To answer this question, the paper offers a typology drawn from reflections on internet usage by focus group respondents, all of whom are experienced internet users. The typology, which is fluid in the sense that internet users may flow from one group to another based on their activities, is then used as a basis for discussion of how ubiquitous access is understood by each user type. The paper considers how an understanding of the characteristics of each type of user might influence the development and adoption of ubiquitous internet access. 


\section{Literature Review}

There is a ubiquitous computing demonstration in the Seoul office of South Korea's Ministry of Information and Communication (see http://www.samsung.com/HomeNetwork/SupportServices/News/view_015.htm for a description of this demonstration), set up to showcase the benefits of ubiquitous computing. Displayed on the wall of this demonstration is the following definition:

"Ubiquitous" derives from a Latin word meaning "omnipresent" or "existing or being everywhere at the same time", and it refers to an environment in which people can use computers and networks anytime, anywhere, in an easy, convenient and safe manner.

While the focus of the Seoul demonstration is ubiquity in the home, ubiquitous computing reaches beyond the home, allowing anytime, anywhere access and providing users with mobility to support a nomadic computing environment (Lyytinen \& Yoo, 2002). As such, in the context of this paper, ubiquitous internet access is achieved by anyone who can access the internet from anywhere, at anytime, in a stationary or mobile environment. Truly ubiquitous access would be achieved when this anytime, anywhere access could be provided on any device. As will be discussed below however, because the demand for ubiquitous internet access is multifaceted, a single access device is not likely to prove satisfactory to all users.

When considering ubiquitous internet access, it is also important to note that there are two components to such access. Described as "infrastructure" and "services" by Lyytinen and Yoo (2002), demand for ubiquitous internet access may be demand just for the network access provided by the ubiquitous infrastructure, or demand for the services that can be provided using this infrastructure. The nature of demand for ubiquitous internet access will be explored below.

Prior to exploring demand for ubiquitous internet access, it is important to consider how the internet is used at present. Given that ubiquitous internet access effectively offers users more 
of the same functionality provided by non-ubiquitous access (i.e. access from single, non-mobile locations in homes, schools and offices), albeit in more locations, understanding current usage behaviours provides a starting point for understanding how ubiquitous internet access could be developed to provide additional value to internet users.

Recent data from the Pew Internet and American Life Project (Rainie \& Bell, 2004) and the UCLA Center for Communication Policy's Internet Project (2003) show that in the U.S., internet uptake has stalled at between $60 \%$ and $70 \%$ of the population. Among the $30 \%$ to $40 \%$ of Americans who do not currently use the internet, many of the non-users indicate they have no intention of ever going online (see Lenhart \& Horrigan, 2003, for a detailed categorization of internet users, ranging from the highly connected home broadband users to the "truly unconnected"). Statistics Canada (2004b) data also show a leveling off of internet usage, and in Korea, "the [high speed internet access] business is coming to a period of maturity and the market is about to reach saturation" (Lee, 2004). While it is likely that internet adoption in countries with widespread internet access and high levels of broadband penetration will continue to be characterized by non-universal uptake, the focus of this paper is on those who are, or have been, internet users, rather than on those who have never used the internet.

Much research conducted on internet usage to date has focused on understanding usage patterns as a function of time spent online (Kestnbaum, Robinson, Neustadtl, \& Alvarez, 2002; Nie, Hillygus, \& Erbring, 2002). The Pew and UCLA data show that as users become more familiar with the internet, they use it in more ways. Rainie and Bell $(2004$, p. 49) report that "users become more serious and expansive in their online activities as they gain experience: the level of experience that a person has online matters a great deal." While they do note that individual usage patterns fluctuate, and that some individuals choose to stop using the internet (either temporarily or permanently), there remains an assumption that users' "levels of 
enthusiasm [for the internet are] tied to their level of use of the internet" (p. 46). This assumption reflects the idea that user experiences are fairly homogenous, and that internet usage types can be accurately described based on exposure to the internet.

The assumption that there are homogenous user groups is frequently generalized to demographic categorization as well, suggesting that younger people are "internet enthusiasts", while older people are most likely to be "internet resisters" (Rainie \& Bell, 2004). This demographic categorization does reflect overall internet adoption patterns by age (Statistics Canada, 2004a; UCLA Center for Communication Policy, 2003), but overlooks the fact that many young people do not use the internet regularly, while many older people do.

Reporting results of a telephone survey, Leung (2003) characterizes the "net-geners," those born between 1977 and 1997, as using the internet widely for a variety of applications including socializing and enjoying the "fluidity of identity" possible on the internet. This research does provide a more nuanced perspective on internet usage within a specific user group, moving away from assumptions of homogeneous experiences. However, the research implies that internet usage is seen as a generally positive experience by the "net-geners", avoiding suggestion that any of the young respondents are nervous or concerned about their use of the internet.

There are studies of internet usage that do question the homogeneous experiences alluded to above. Howcroft (1999) cuts through the rhetoric that establishes the internet and information as necessarily useful. In her study she interviews experienced internet users (who had used the internet for a minimum of one year, and who used it as part of their job), finding that, "more often than not, the consequences of internet usage are situated at some point along a continuum from utopia to dystopia; it is useful for some people for some of the time, for some particular purpose" (p. 277). In fact, many of her interviewees did not find the 
internet useful all the time. Katz and Rice (2002) report on the phenomenon of "internet dropouts" - people who used the internet previously, but have since stopped using it, noting that after the initial period of interest, the internet is simply not relevant to some people. Similarly, Horrigan and Rainie (2002) discover that people's use of the internet for "serious email" expressing feelings or discussing issues, drops off after one year. They attribute this dropoff to a waning of interest as the internet's novelty wears off.

This literature suggests that there is a need for more nuanced categorizations of internet use that take into account the range of responses even experienced internet users have toward the internet. In what follows we argue that there is in fact a great range of feelings about the internet on the part of those who use it. These more complex feelings about the internet may reflect a certain fatigue with the medium that results from its increasing ubiquity, or they may be indicative of a general ambivalence toward the technology.

We would like to propose a more sensitive classification of internet users and their experiences based on data collected in nine focus groups. In keeping with previous qualitative research about internet use, these focus groups examine people's responses to and activities on the internet, in order to better understand how they engage with the technology and the applications it enables. Since excellent quantitative data has already begun to frame some of the issues related to internet use, we have employed qualitative methods, to better understand the specifics of people's feelings about the internet. As Hargittai (2004) points out, while broad survey data provide excellent frameworks for beginning studies of internet users, they do not always allow for a full understanding of people's experiences of the internet.

\section{Methodology}

The discussion presented here is based upon findings from focus group discussions with experienced internet users. All participants in this study had used the internet extensively and 
many reported regular high-speed access from several locations. Most respondents had access to a broadband connection in their homes. While these respondents are not representative of the entire population of internet users, it is the behaviours and attitudes of experienced users such as these that are of interest when considering how ubiquitous internet access might be developed and adopted.

A total of 60 people participated in the nine focus groups. The gender balance was almost even, with 26 male participants and 34 female participants. The age of participants ranged from 14 to 63 , with the majority of respondents aged between 16 and 30 . Almost all respondents were students, in high school, or completing undergraduate or graduate studies at university. Focus groups were conducted in two Canadian cities, between May 2003 and July 2004. One focus group was conducted in French.

All focus groups were audiotaped, and the tapes were professionally transcribed. All authors were involved in analyzing the data, which were coded by the two lead authors and then merged into a single coded data base, using N6 software.

\section{Findings}

The first research question addressed in this paper is "How do experienced users use the internet?" We found four types of internet users among the focus group participants: the "dropout", the "suspicious" user, the "instrumental" user and the "extremely connected" user. Each type of user is described below. Although some users exhibited characteristics belonging to more than one user type (i.e. their internet usage is dynamic), the data indicate that the four user types are distinct. Individuals' main internet usage behaviours and patterns can be situated within one usage type. 


\section{Four Types of Internet Users}

\section{The Dropout}

None of the respondents in our focus groups had managed to completely drop out of his or her internet activities and stay offline all the time, but the users we labelled as "dropouts" recognized that they could exist happily, much of the time, without internet connections. A high school student reflects on this point, saying "I can actually do without the internet, and yet it plays a huge part in my teenage life. For a lot of people now, it's such a huge deal." But for the dropouts we talked to, the internet is not "such a huge deal." The novelty of the internet has worn off, and the dropouts want to get away from electronic communication, as this university student explains:

I don't want to be only electronically connected ... I'm tired of it, that's why. Because I'd rather them [friends] call me instead, rather than leave a message. I found that really impersonal. And now it's come to a point where I just won't turn it on. If you want to contact me, contact me through other means.

This university student expressed fatigue with broadband applications:

I had a bit of an overdose of it, because I just downloaded so much music that I just got sick of it... all these songs. I've already deleted so many of them, because I just got sick of it. I haven't downloaded music in months.

Rather than being enticed by broadband marketing that suggests that "faster is better", dropout users were trying to figure out the cheapest way to maintain a minimal level of internet access. Some had switched from broadband connections back to dial up access, or to "basic" (sometimes called "lite") service offered by broadband providers (e.g. 256 Kbps always-on service). The internet is not a central technology in dropouts' lives, as these two quotes from high school students demonstrate:

For me, I find that I'm never use the internet unless I'm around the school, in a school environment. On the weekends, I never think about the internet. On the holidays, I don't think about the internet. 
I was thinking when I was on holiday, "Why aren't I at all interested in finding an internet café and checking my e-mail?" And I really wasn't interested. ... I really enjoy the break. It's not that I can't do it, it's really that you choose not to.

The dropouts in our study hadn't dropped out entirely, and probably won't completely disengage from using the internet in future. But in contrast to the other types of users encountered in this study, the internet does not always play a large role in the lives and daily activities of the dropouts.

\section{The Suspicious User}

The second type of user we identified among our respondents was the suspicious user. Like the dropouts, these users were somewhat uncomfortable with their internet usage, but unlike the dropouts, the suspicious users continued to use the internet in many ways.

Suspicious users were very mindful of their internet usage, and had many concerns about the internet. Suspicious users perceive the internet as useful but unreliable, as this comment shows:

Je crois que c'est très utile et c'est une source illimitée d'information mais c'est pas comme un bon vieux livre, c'est pas la même chose. C'est pas comme vous lisez quand vous faites internet, ça veut dire le livre, il peut pas tomber en panne. Le livre il ne peut pas tomber en panne.

[Translation: I think that it's very useful and it's an unlimited source of information, but it's not like a good old book, it's not the same thing. It's not like you're reading when you're on the internet, that's to say that a book, it doesn't break down. A book, it doesn't break down.]

Broadband internet connections, which are always connected, are seen as potentially dangerous to users' computers:

I feel like my computer is constantly vulnerable to viruses and stuff like that, and spyware ... whenever it's on it's connected to the internet, so I feel like I'm going to get more viruses or something.

This type of user is not confident that sensitive data can be protected online, and is wary of providing personal information over the internet, suggesting for example that "it would be convenient, but dangerous." Another participant in the same focus group echoed this concern, 
noting, "It's kind of scary that you are sending out all this information and you don't know where it's going." The concern was widespread:

It would be risky... all your personal stuff would be just out there. I'm sure hackers could just hack into the websites, and get stuff without their permission.... I wouldn't want my information to be all over the place.

Anybody could hack into the system. I don't know how they would do it, but they would see your personal information and they could steal your identity.

When asked how they felt about online health services, high school students responded with, "That's kind of scary", "That would just be frustrating", and "I want to see the doctor". Another high school student wondered:

"What about if you have some sort of rash or skin problem? How are they going to see what's wrong with you? They can't really look at you. They can see your face in the web-cam, but they can't really check... they can't touch, they can't take your temperature."

Talk of online elections had these high school students worrying about security issues.

The security part of it would be... I wouldn't want to do it. Or I would be afraid somebody... it would just be too easy for somebody else to manipulate.

Somebody could just change a bunch of votes or make up a whole bunch of votes.

Another concern among suspicious users is that they cannot effectively control their internet experiences, and are often subjected to spam, pop-up ads and other online annoyances that detract from their usage of the internet. Some high school students express their irritation in this regard:

It's so frustrating when you get spam, because you'll log into your account and it will say, "You have 10 new messages," and eight of them will be advertising. It's so frustrating.

If too many people send you huge forwards and it's stupid pictures and like that, it uses up your entire storage. I've e-mailed my friends and said, "Don't send me any more forwards. Those ones that are like, "If you don't send them to ten people, you're going to be hit by a truck!" "Or you're going to be lonely for the rest of your life." So I'm lonely. Who cares! 
I find them [forwards] so annoying. They take up all your room so then people can't e-mail you. If you don't check your e-mail for five days, you can get all these stupid forwards, and it's not like the forward is really important e-mail.

Suspicious users are also conscious that using the internet often leads to wasting time, and are wary of internet addiction. A university student comments:

I go on the internet thinking I will check my e-mail for 15 minutes, but it comes out to many hours, because people are messaging me, and I have so much email, and there's so much stuff to do, so it takes a lot of time. And I'm supposed to do homework, and I don't do homework, and I go online.

Other students in the focus group share this awareness, noting:

It's time consuming. And also to find what I want online, I spend most of the time wasting it and not doing anything productive. There's just something that will suck you into it once you're online. "Go on. Waste your time."

It's addictive sometimes, because when I come home during the weekend, I spend a fair deal of time compared to the regular weekdays. It can be addictive at times. It was addictive to me in the beginning.

I've noticed I've become more lazy. I see less of outdoors, now. I've kind of become addicted to things like MSN and message boards where I stay at home and I chat rather than going outside. Like, [my] gut's kind of paying for that!

In summary, suspicious users are not entirely convinced of the value of the internet. They do use the internet, but are convinced of its flaws, and of the negative aspects of regular internet usage.

\section{The Instrumental User}

Instrumental users express fewer concerns about their usage of the internet than suspicious users, but have not fully integrated the internet into their lives. They exhibit some ambivalence toward the internet, and tend to develop rules to govern their internet usage. An instrumental user carefully considers the value of the internet, and has a purpose for using it. For example, a high school student explains a situation where she chooses to use the internet, saying, "I don't really use the computer, except my best friend's in Africa, so we use it once a week." 
Instrumental users recognize the value of the internet in different situations, for example as

a means of accessing information when it is not possible to physically go to a library:

I'm where I don't have access to a car or any type of library where I can get books, because the library out here closes... So it [the internet] was pretty much... it's pretty much a source of information. It's really easy to just get online and search for something.

In some instances, the internet is valuable when accessed through a device other than a

computer, for example using text messaging on a cell phone:

If my parents go away, it's cheaper just to write [SMS] them. When I go to Montreal to visit my sister and they want me to check in... it costs fifteen cents, right, so it's better just to write, "Okay, I'm here. How are you?"

Another example is provided with this description of e-mail:

I find that it's [e-mail] kind of like an answering machine. If you have something to say to someone, you can set up the e-mail whether they're there or not. They'll find out later and they can either call you or e-mail you back. It's just kind of convenient. Everybody's so busy these days that you can't always get a hold of them. If you could have something just sitting there waiting, when they get home they can read it and your point will still get across to them, and no one will get left out or nothing will be forgotten. It's just really convenient, I find.

Instrumental users are aware of the concerns expressed by suspicious users, and develop online behaviours to mitigate negative aspects of the internet. For example, to counter the time-wasting, addictive nature of the internet, and to avoid interruptions, one graduate student disconnects from the internet.

I have to turn the internet off if I'm writing a paper or something, because it's like, for me it's like having music in the background or something. I just can't concentrate. I'm like, "Oh, maybe someone's going to e-mail me back." So I check it, and then totally derail my train of thought. It's just a disaster. I have to cut myself off.

Another suggests "One of the reasons I bought a laptop was so I could close it and make it go away, so I don't have to look at a computer all day." 
An instrumental user thinks carefully about how he or she will access the internet. A high school student explains that he's not using broadband yet, but if he were to get broadband it would be so that he could quickly download games and other large programs:

Je ne suis pas encore à haute vitesse mais si je déciderai ce serait pour télécharger des jeux et beaucoup d'autres logiciels qui sont assez volumineux. Avec internet haute vitesse je pourrais télécharger très vite.

A graduate student outlines his decision making process:

I specifically chose to get high speed. The decision was made because I decided that I wanted to start downloading music. I wasn't before. And I actually calculated how much I spent per month on CDs and then how much I would spend per month on high speed, and decided that it was cheaper to get high speed and not buy CDs anymore. So that's what I've done ever since. I think I've bought one $C D$ in the last two years.

For instrumental users, usage is often context dependent. The internet is used in different ways in different places, as this example shows:

I just find when I'm at school I just use the internet really super quickly and get off, whereas at home I can spend probably hours wasting time ... When I first moved here, it was a month before I could get on the internet for some reason, and I used to go to a café, and I wouldn't mind spending time even though it's crowded and loud and stuff. But because I could do everything that I wanted to do. I felt like I could research and I could do Messenger, but at school they restrict you...

To assuage concerns related to issues of security and privacy, this university student described differences in online behaviours based on whether or not the internet was accessed from home or school:

It's really strange, I find that... I got into online buying last semester, but the thing is, even though I had an Internet connection over here [at university]... I wouldn't feel safe buying online here. I would go home and purchase it. That's really weird. I noticed that. I'm just not comfortable when I'm here, even though I have the capability to do that.

But I use that very same computer [laptop], take it home, plug it into my network, and I use that same computer to buy online, but I just don't have that...I think it's that comfort level at home. 
Instrumental users are comfortable using the internet, but for these users, the internet is used for specific purposes in particular circumstances. Instrumental users recognize that the internet is valuable, but it is primarily a tool. As a tool, the internet is used when needed, but it is not needed all the time.

\section{The Extremely Connected User}

Extremely connected users are unlike other user types in that the internet has become an integral part of their lives. The idea of "going on the internet", as a distinct activity, seems strange to these users, as their expectation is that the internet is "on" and accessible wherever they go. The internet is not something that these users consciously turn on and off (as other types of users do), it is simply part of the backdrop of their lives. As one graduate student commented when asked why he used the internet, "that question to me is kind of a moot point, these days. I don't know how you can even survive without it." An undergraduate reflects a similar viewpoint, saying "I think I would feel socially crippled if I didn't have the internet."

Leaving the computer on all the time, with the internet "running" in the background, is a common practice for the extremely connected user, as these comments from undergraduate students demonstrate:

Now, with [broadband], it's always on, always connected, and now it's unlimited [bandwidth] up and down, my computer hasn't been off in the last month or so.

Now, with cable and my TV right there, and my laptop right in front of me I have no reason to leave my seat unless it's time for dinner and stuff, because I get everything done there. So it's not uncommon for me to be sitting there for a long time, like hours.

For me, I probably sit in front of computers 16 hours a day, and then 8 hours of sleep. That makes 24 hours already! I'm the only child at home, so I prefer ICQ and anything where I can actually talk to people, and if everyone else is busy then I go on-line and play games or listen to music, in which case I will probably still be sitting in front of that computer, or looking for something on the web.

I use it all... every day at home, and at school if I have to, but I have high speed at home so I'm generally on it all the time, checking e-mail, I use MSN Messenger to chat with friends and family, and basically doing library searches, 
journal searches, database searches. That's about it, I guess. Oh... and I download music, sometimes...

These users expect their internet connections to be available all the time, and to be fast and reliable:

I mean, I have access to broadband at home, at school, when I go to internet cafés. Just the ability to get something when you ask for it is... it's become sort of an expectation that I've had, so subconsciously if it takes longer then I lose interest in it.

If the internet connection is perceived to be of poor quality in one location, the extremely

connected user will seek out a better connection elsewhere, as this graduate student explains:

Actually, this afternoon my supervisor offered me office space that I just simply didn't take because the connection at the school is slower. And he said, "You don't want office space?" I said, "Yeah, your computers are slow. I log in and it takes me 15-20 seconds to get my e-mail. And that's just too slow, if I'm checking my e-mail, I don't know... every 10, 15, 20 minutes. And then if I'm looking for data sets online, it's just too slow. I don't know, I feel that my time is better spent if I could just get things done now.

Using the internet is second nature for the extremely connected user, as this teenager explains:

This might sound really silly, but my computer's upstairs, my sister's is downstairs, so if someone calls and I pick up and it's her friend, I hate going all the way downstairs so I'll just pop up MSN and be like, "Hey, [sis], phone." She'll pick up the phone and I don't have to scream!

The internet is part of extremely connected users' daily routines:

Every day, part of my daily routine is checking out my friend's blogs, reading... updating my own, and just checking things out that way. And also just Messenger all the time now, whereas before I never Messengered. So it's definitely gotten integrated into my daily routine.

Typical of the extremely connected user, these high school students can't imagine life without internet access:

Personally, I use it every day. If I'm away from home and I have to talk with my family and friends or anything, I just use MSN every day, and I do it every day, all the time, pretty much all the time I'm online, MSN. It's a part of my life. If I don't have it, I don't know what to do, I think. 
I think it's been around so long, it's sort of a part of your life. If you removed it globally, everywhere, it would just be too weird. It's already grown to be a part of your life so much you can't live without it.

The extremely connected users' comments presented above demonstrate the differences between this type of user and the other three user types presented earlier. For the extremely connected, the internet is simply a part of their lives. In Silverstone and Haddon's (1996) terminology, these users have domesticated the internet. They are well aware of the shortcomings of the internet, but cannot imagine a world without it. They have moved beyond instrumental usage, into an environment where fast internet access is expected to be available at anytime, to be used in a myriad of ways.

\section{Summary}

As the data above show, there are a variety of internet usage behaviours among experienced internet users. While some literature suggests that as users become more experienced with the internet they use it more frequently and for a wider variety of activities, we found that this was not the case for all users. Only the "extremely connected" users exhibit these behaviours, while some others actually disengage from the internet over time.

Overall, our data do reflect a wide diversity of internet usage patterns, contradicting the assumption that experienced users act in homogeneous ways. We did not find a pattern between the age of the user and type of internet behaviour. For example, there were young high school students whose behaviours were typical of the dropout user, and older graduate students who were instrumental or extremely connected users.

We have categorized the observed behaviours in terms of static user types, but it is important to note that there is some dynamism in user behaviours. For example, instrumental users may exhibit characteristics of suspicious users in some circumstances. Suspicious users may tend toward dropout behaviours on occasion. What is important in the context of understanding demand for ubiquitous internet access is the finding that there are distinct 
patterns of internet usage among experienced internet users. This means that the answer to the question "should the internet be everywhere?" will be dependent upon the user type of the person queried, as is discussed below.

\section{Implications for the Ubiquitous Internet}

We believe that it is reasonable to assume that different types of internet users will have different perspectives on the value of ubiquitous internet access. In this section, we outline the nature of services, infrastructure and devices that are likely to be of interest to different types of internet users in a ubiquitous internet environment. We also offer some recommendations for the development of ubiquitous services.

The term services refers to activities that can be carried out on the internet. Broadly defined, services could be provided in the areas of education (e.g. online learning and access to sources of knowledge), entertainment (e.g. delivery of movies, music and television over the internet), healthcare (e.g. access to health information and to healthcare providers, telemedicine), and e-commerce. Government services (e.g. access to municipal information, online voting, completion of forms, filing of documents, fee payments, etc.) could also be offered in a ubiquitous environment.

In a truly ubiquitous environment, internet access would be available everywhere. This would require extensive infrastructure (i.e. physical network capacity), to ensure that any user could connect any device to the internet, in either a fast moving mobile environment (e.g. automobile, train, airplane) or a fairly static one (e.g. moving around within an office or home). The development of infrastructure to provide truly ubiquitous access is dependent upon the technical capabilities of access technologies (3G, 802.11b/g Wi-Fi, Wi-Bro etc.) and on the development of appropriate business models that will ensure sufficient revenues to justify such infrastructure investment. 
Devices that could be used to access the ubiquitous internet include mobile telephones, handheld computing devices (e.g. PocketPC, PalmPilot, Blackberry) and laptop or tablet computers.

Each type of internet user will respond to the availability of ubiquitous internet access in a different way. For instance, it is expected that dropout users will choose not to access services that are available over the internet, even if ubiquity makes it easier to access services from multiple locations. Suspicious users are not likely to be comfortable accessing the internet from multiple locations, even though ubiquity makes this possible. They are concerned about privacy and may not be satisfied that public internet access points are sufficiently secure. In contrast, extremely connected users will welcome the opportunity to use the internet wherever they go, and will use multiple devices to establish internet connectivity.

The tables below outline important issues to consider as ubiquitous internet access is made available to each type of internet user. The tables synthesize comments made by focus group participants on the value of ubiquity, and then address the implications of these comments.

\begin{tabular}{|c|c|c|c|c|}
\hline User Type & Dropout & Suspicious & Instrumental & $\begin{array}{l}\text { Extremely } \\
\text { connected }\end{array}$ \\
\hline \multicolumn{5}{|l|}{ Services } \\
\hline $\begin{array}{l}\text { What kind of } \\
\text { ubiquitous } \\
\text { services will be } \\
\text { of interest? }\end{array}$ & $\begin{array}{l}\text { Not interested in } \\
\text { internet-based } \\
\text { services. } \\
\text { Derive no value } \\
\text { from ubiquitous } \\
\text { availability of } \\
\text { services. }\end{array}$ & $\begin{array}{l}\text { Wary of services } \\
\text { that require online } \\
\text { disclosure of } \\
\text { personal } \\
\text { information. }\end{array}$ & $\begin{array}{l}\text { Convenience and } \\
\text { ease of use will } \\
\text { determine which } \\
\text { services are used. }\end{array}$ & $\begin{array}{l}\text { Willing to try any } \\
\text { type of ubiquitous } \\
\text { service. } \\
\text { High comfort level } \\
\text { with online } \\
\text { payments and } \\
\text { service delivery, } \\
\text { confident that } \\
\text { personal } \\
\text { information can be } \\
\text { kept secure. }\end{array}$ \\
\hline $\begin{array}{l}\text { Implications for } \\
\text { developing } \\
\text { ubiquitous } \\
\text { services? }\end{array}$ & $\begin{array}{l}\text { Moving services to } \\
\text { internet-only } \\
\text { delivery will } \\
\text { exclude dropouts. } \\
\text { Services should be }\end{array}$ & $\begin{array}{l}\text { Lack of trust in } \\
\text { service providers, } \\
\text { including } \\
\text { government } \\
\text { agencies, suggests }\end{array}$ & $\begin{array}{l}\text { Differing } \\
\text { assessments of } \\
\text { convenience and } \\
\text { ease of use will } \\
\text { mean that a variety }\end{array}$ & $\begin{array}{l}\text { Will be early } \\
\text { adopters of } \\
\text { ubiquitous services. } \\
\text { Service providers } \\
\text { can work with }\end{array}$ \\
\hline
\end{tabular}




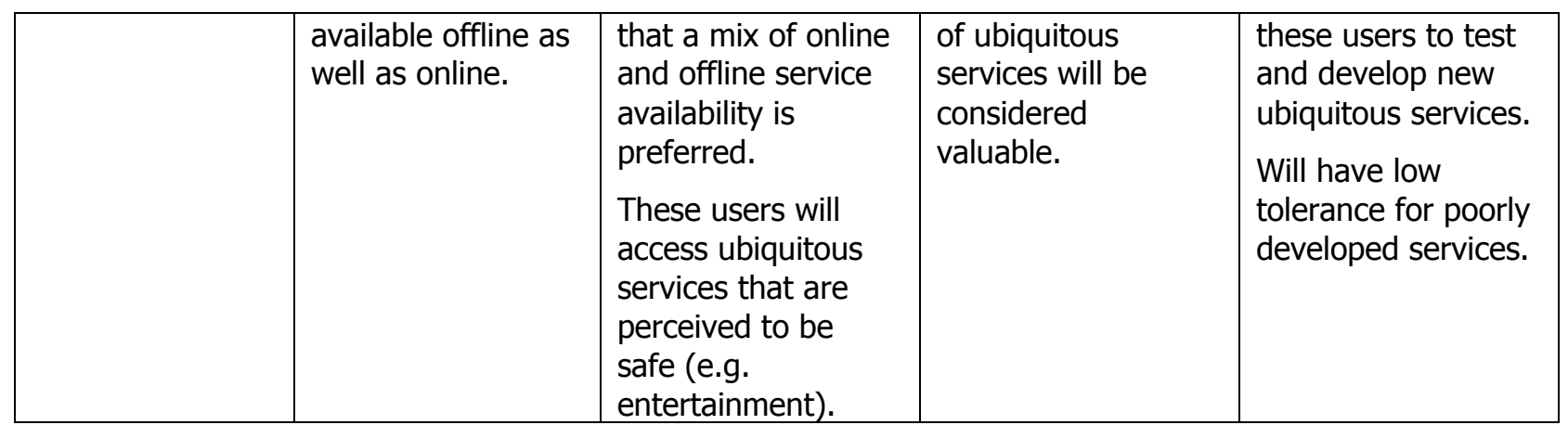




\begin{tabular}{|c|c|c|c|c|}
\hline User Type & Dropout & Suspicious & Instrumental & $\begin{array}{l}\text { Extremely } \\
\text { connected }\end{array}$ \\
\hline \multicolumn{5}{|l|}{ Infrastructure } \\
\hline $\begin{array}{l}\text { Where will the } \\
\text { ubiquitous } \\
\text { internet actually } \\
\text { be used? }\end{array}$ & $\begin{array}{l}\text { No demand for } \\
\text { ubiquitous access. }\end{array}$ & $\begin{array}{l}\text { Limited demand for } \\
\text { ubiquitous access. } \\
\text { Will appreciate } \\
\text { secure mobile } \\
\text { access within } \\
\text { home, office and } \\
\text { school locations, } \\
\text { but not likely to } \\
\text { demand access } \\
\text { when moving } \\
\text { between locations. } \\
\text { May use public } \\
\text { internet access } \\
\text { points but will } \\
\text { remain wary about } \\
\text { providing personal } \\
\text { information over a } \\
\text { public network. }\end{array}$ & $\begin{array}{l}\text { Demand for access } \\
\text { is driven by need, } \\
\text { convenience and } \\
\text { cost. Instrumental } \\
\text { users may find } \\
\text { value in Wi-Fi } \\
\text { networking within } \\
\text { the home, office or } \\
\text { educational } \\
\text { environment. } \\
\text { Ubiquitous access } \\
\text { will be used for } \\
\text { specific services at } \\
\text { specific times (e.g. } \\
\text { checking e-mail } \\
\text { while traveling), if } \\
\text { the cost is } \\
\text { perceived to be } \\
\text { reasonable. }\end{array}$ & $\begin{array}{l}\text { High demand for } \\
\text { internet access in } \\
\text { multiple locations. } \\
\text { Likely to have a Wi- } \\
\text { Fi network at } \\
\text { home. } \\
\text { Willingness of } \\
\text { extremely } \\
\text { connected users to } \\
\text { pay for ubiquitous } \\
\text { access is untested. }\end{array}$ \\
\hline
\end{tabular}




\begin{tabular}{|c|c|c|c|c|}
\hline User Type & Dropout & Suspicious & Instrumental & $\begin{array}{l}\text { Extremely } \\
\text { connected }\end{array}$ \\
\hline \multicolumn{5}{|l|}{ Devices } \\
\hline $\begin{array}{l}\text { What are the } \\
\text { preferred } \\
\text { devices for } \\
\text { accessing the } \\
\text { ubiquitous } \\
\text { internet? }\end{array}$ & $\begin{array}{l}\text { No demand for } \\
\text { ubiquitous access. }\end{array}$ & $\begin{array}{l}\text { Users are unlikely } \\
\text { to acquire new } \\
\text { devices to be used } \\
\text { specifically for } \\
\text { internet access, but } \\
\text { may use existing } \\
\text { devices (e.g. } \\
\text { mobile phone, } \\
\text { desktop computer) } \\
\text { to access desired } \\
\text { services. } \\
\text { May access services } \\
\text { in public spaces if } \\
\text { access devices are } \\
\text { provided (e.g. } \\
\text { kiosk-based service } \\
\text { delivery). } \\
\text { Service providers } \\
\text { may wish to } \\
\text { downplay the fact } \\
\text { that certain } \\
\text { services are being } \\
\text { delivered using the } \\
\text { internet, for } \\
\text { example by } \\
\text { designing secure } \\
\text { access devices that } \\
\text { do not look like } \\
\text { computers. }\end{array}$ & $\begin{array}{l}\text { Devices are } \\
\text { adopted for their } \\
\text { usefulness. } \\
\text { Service providers } \\
\text { should design } \\
\text { services to be } \\
\text { delivered to the } \\
\text { most widely used } \\
\text { access devices, like } \\
\text { mobile phones. } \\
\text { If needed, } \\
\text { instrumental users } \\
\text { may carry laptops } \\
\text { for internet access. } \\
\text { Internet access } \\
\text { may also be sought } \\
\text { in internet cafés. } \\
\text { The cost of access } \\
\text { devices is a } \\
\text { relevant factor for } \\
\text { instrumental users, } \\
\text { they are looking for } \\
\text { value for money. }\end{array}$ & $\begin{array}{l}\text { Extremely } \\
\text { connected users } \\
\text { will use multiple } \\
\text { access devices, } \\
\text { including mobile } \\
\text { phones and PDAs. } \\
\text { Laptops may be } \\
\text { used to access } \\
\text { some services, but } \\
\text { are considered } \\
\text { unwieldy in a } \\
\text { mobile context. }\end{array}$ \\
\hline
\end{tabular}

The tables suggest that of the four user types, only the extremely connected user is currently ready to embrace ubiquitous internet access. This is an important finding as it calls into question the assumption that the internet should be everywhere. 


\section{Discussion and Conclusions}

Our focus group discussions reveal that far from being embraced unconditionally, the internet is considered to be valuable only in certain contexts -- contexts which depend to a large extent on non-technological factors. The value of the internet seems to be closely related to the internet's perceived utility (consistent with the findings of the technology acceptance model, see Davis, 1989). A desire for ubiquitous internet availability does not necessarily arise from ongoing internet use, even among experienced internet users. In fact, users who feel they "need" the internet frequently indicate that they do not necessarily "want" it. As experienced users, focus group participants understand the internet's applications and value, but many are resistant to acquiring or using a permanent or ubiquitous connection to the internet.

We found that dropouts, and suspicious, instrumental and extremely connected users, have different levels of demand for ubiquitous internet access. The dropouts, or prior heavy internet users, have an aversion to ubiquitous high-speed internet. Suspicious users demonstrate apprehension toward ubiquity, and increased availability of the internet would be unlikely to change their perceptions of its value. Suspicious users are often concerned with having offline options to access services that are moving online, like government and health services. Instrumental users favour controlled, or selective ubiquity. For the times, places, and applications they consider high-speed internet to be valuable, they find it necessary and want it to be readily accessible. However, this perceived value is not present throughout all facets of their lives and daily routines. When the internet is not deemed to be beneficial, ubiquity is unwelcome, particularly when it erodes barriers between personal and work spaces. Extremely connected users are those experienced users that regard ubiquitous broadband as desirable, and who would most benefit from ubiquitous internet access. Researchers considering the impacts of "internet everywhere" would be well-advised to focus their studies on this group of 
users. Similarly, developers of ubiquitous access products or services will also want to focus their development to target this group of users.

One limitation of this research is that we did not consider users' willingness to pay for ubiquitous access. We do know though that many users are simply not interested in full-blown ubiquitous access at present, so will not pay for it. As such, we suggest that it will be difficult in the short term for businesses to generate steady revenue streams through the provision of ubiquitous internet access services that appeal primarily to the extremely connected user. For example, even after several years of availability, there still appears to be very limited demand to access the internet through fee-for-service wireless hotspots (Jamaluddin, Doherty, Edwards, \& Coulton, 2004; Stone, 2003), an observation consistent with the assessment of demand for ubiquity presented here. In contrast, a form of ubiquitous access that is more appealing to a wider group of users, including instrumental users, the internet café, appears to be thriving, perhaps because it offers more to its users than just internet access (Middleton, 2003; Powell, 2003). This observation highlights the importance of building ubiquitous access and services in ways that will suit various internet user types.

A second limitation of this research is that our focus groups did not include business users who rely heavily on the internet to carry out their day to day business activities. The context in which they use the internet is quite different from that of the students with whom we spoke. It is expected that the same user types are present within the community of business internet users, but it is likely that there are proportionately higher numbers of extremely connected and instrumental users, and fewer dropouts and suspicious users. Rather than speculate here on the nature of demand for ubiquitous internet access among business users, it is suggested that a study of this community be carried out as a separate project. 
We believe that our findings make a valuable contribution to understanding the nature of demand for ubiquitous internet access. Our findings challenge the assumption that there will be widespread demand for ubiquitous internet access in the near future, as only one of four user types identified here, the extremely connected user, is ready to integrate such access into daily routines and activities. More research is needed to better understand the longer term prospects for ubiquitous internet access. While our research shows that there is resistance to ubiquitous access among many experienced internet users, we do not know what the future will bring as more people adopt the internet. We believe that the categories of usage we observed will persist over time, but as the internet becomes more entrenched in society, it may be more difficult for those who want to drop out to do so. Suspicious users may find that their current fears are allayed as internet access technologies become more sophisticated, but new concerns may arise. Wider internet availability could lead to the development of valuable new services that might be attractive to suspicious users and even possibly encourage dropouts to re-engage with the internet. The key to development of successful new services is an understanding of what various user groups want, and how ubiquitous internet access can provide value to them. 


\section{Bibliography}

Broadband Advisory Group. (2002). Australia's Broadband Connectivity. Canberra: National Office for the Information Economy.

Computer Science and Telecommunications Board. (2002). Broadband: Bringing Home the Bits. Washington, DC: National Academy Press.

Davis, F. D. (1989). Perceived Usefulness, Perceived Ease of Use, and User Acceptance of Information Technology. Management Information Systems Quarterly, 13(2), 319-340.

Dixit, S. (1999). Data Rides High on High-Speed Remote Access. IEEE Communications Magazine, 37(1), 130-141.

Hargittai, E. (2004). Classifying and Coding Online Actions. Social Science Computer Review, 22(2).

Horrigan, J. B., \& Rainie, L. (2002). Emails That Matter: Changing Patterns of Internet Use over a Year's Time. IT \& Society, 1(1), 135-150.

Howcroft, D. (1999). The Hyberbolic Age of Information: An Empirical Study of Internet Usage. Information, Communication and Society, 2(3), 277-299.

International Telecommunication Union. (2003a). Birth of Broadband. Geneva: ITU.

International Telecommunication Union. (2003b). Digital Access Index. Retrieved 7 September, 2004, from http://www.itu.int/ITU-D/ict/dai/

Jamaluddin, J., Doherty, M., Edwards, R., \& Coulton, P. (2004). A Hybrid Operating Model for Wireless Hotspot Businesses. Paper presented at the IEEE Consumer Communications and Networking Conference.

Katz, J. E., \& Rice, R. E. (2002). Social Consequences of Internet Use: Access, Involvement and Interaction. Cambridge, MA: MIT Press.

Kestnbaum, M., Robinson, J. P., Neustadtl, A., \& Alvarez, A. (2002). Information Technology and Social Time Displacement. IT \& Society, 1(1), 21-37.

Lee, Y.-K. (2004, 8 September). Korea Moving to Ubiquitous Networking. Korea Herald (online edition).

Lenhart, A., \& Horrigan, J. B. (2003). Revisualizing the Digital Divide as a Digital Spectrum. IT \& Society, 1(5), 23-39.

Leung, L. (2003). Impacts of Net-Generation Attributes, Seductive Properties of the Internet, and Gratifications-Obtained on Internet Use. Telematics and Informatics, 20(2), 107129.

Lyytinen, K., \& Yoo, Y. (2002). Research Commentary: The Next Wave of Nomadic Computing. Information Systems Research, 13(4), 377-388.

Middleton, C. A. (2003). Broadband Internet Usage Outside the Home: Insights from a Study of Toronto Internet Cafes. Paper presented at the International Telecommunications Society Asia-Australasian Regional Conference, Perth, Australia.

National Broadband Task Force. (2001). The New National Dream: Networking the Nation for Broadband Access. Ottawa: Industry Canada.

Nie, N. H., Hillygus, D. S., \& Erbring, L. (2002). Internet Use, Interpersonal Relations, and Sociability: A Time Diary Study. In B. Wellman \& C. Haythornthwaite (Eds.), The Internet in Everyday Life (pp. 215-243). Oxford: Blackwell Publishing.

Office of the e-Envoy. (2001). UK Online: The Broadband Future. An Action Plan to Facilitate Roll-out of Higher Bandwidth and Broadband Services.

Powell, A. (2003). E-Life and Real Life: On- and Off-Line Social Life in an Internet Café. Paper presented at the Association of Internet Researchers Annual Conference, Toronto. 
Rainie, L. (2004). The Rise of Wireless Connectivity and Our Latest Findings: A PIP Data Memo. Washington, DC: Pew Internet and American Life Project.

Rainie, L., \& Bell, P. (2004). The Numbers That Count. New Media and Society, 6(1), 44-54.

Silverstone, R., \& Haddon, L. (1996). Design and Domestication of Information and Communication Technologies: Technical Change and Everyday Life. In R. Mansell \& R. Silverstone (Eds.), Communication by Design: The Politics of Information and Communication Technologies (pp. 44-74). Oxford: Oxford University Press.

Statistics Canada. (2004a). CANSIM, Table 358-0004. Retrieved 23 August, 2004, from http://www.statcan.ca/english/Pgdb/arts54a.htm

Statistics Canada. (2004b, 8 July). Household Internet Use Survey 2003. Retrieved 8 September, 2004, from http://www.statcan.ca/Daily/English/040708/d040708a.htm

Stone, A. (2003). For-Fee Hot Spots Strive to Make Wi-Fi Pay. IEEE Pervasive Computing, JulySeptember, 3-7.

UCLA Center for Communication Policy. (2003). The UCLA Internet Report: Surveying the Digital Future Year 3. Los Angeles: UC Regents.

Wanichkorn, K., \& Sirbu, M. (2002). The Role of Wireless Access Networks in the Deployment of Broadband Services and Competition in Local Telecommunications Markets. Paper presented at the Telecommunication Policy Research Conference, Alexandria, Virginia. 